\title{
Article \\ The Influence of Mental Imagery Expertise of Pen and Paper Players versus Computer Gamers upon Performance and Electrocortical Correlates in a Difficult Mental Rotation Task
}

\author{
Johannes Rodrigues *(D), Dorna Marzban and Johannes Hewig (D) \\ Department of Psychology I: Differential Psychology, Personality Psychology and Psychological Diagnostics, \\ Julius-Maximilians-University of Würzburg, 97070 Würzburg, Germany; \\ dorna.marzban@stud-mail.uni-wuerzburg.de (D.M.); hewig@psychologie.uni-wuerzburg.de (J.H.) \\ * Correspondence: johannes.rodrigues@uni-wuerzburg.de; Tel.: +49-931-31-81771
}

check for updates

Citation: Rodrigues, J.; Marzban, D.; Hewig, J. The Influence of Mental Imagery Expertise of Pen and Paper Players versus Computer Gamers upon Performance and Electrocortical Correlates in a Difficult Mental Rotation Task. Symmetry 2021, 13, 2337. https://doi.org/10.3390/ sym13122337

Academic Editors: Kazuhiko Sawada and Sebastian Ocklenburg

Received: 28 October 2021

Accepted: 30 November 2021

Published: 6 December 2021

Publisher's Note: MDPI stays neutral with regard to jurisdictional claims in published maps and institutional affiliations.

Copyright: (c) 2021 by the authors. Licensee MDPI, Basel, Switzerland. This article is an open access article distributed under the terms and conditions of the Creative Commons Attribution (CC BY) license (https:/ / creativecommons.org/licenses/by/ $4.0 /)$.

\begin{abstract}
We investigated the influence of mental imagery expertise in 15 pen and paper roleplayers as an expert group compared to the gender-matched control group of computer role-players in the difficult Vandenberg and Kuse mental rotation task. In this task, the participants have to decide which two of four rotated figures match the target figure. The dependent measures were performance speed and accuracy. In our exploratory investigation, we further examined midline frontal theta band activation, parietal alpha band activation, and parietal alpha band asymmetry in EEG as indicator for the chosen rotation strategy. Additionally, we explored the gender influence on performance and EEG activation, although a very small female sample section was given. The expected gender difference concerning performance accuracy was negated by expertise in pen and paper role-playing women, while the gender-specific difference in performance speed was preserved. Moreover, gender differences concerning electro-cortical measures revealed differences in rotation strategy, with women using top-down strategies compared to men, who were using top-down strategies and active inhibition of associative cortical areas. These strategy uses were further moderated by expertise, with higher expertise leading to more pronounced activation patters, especially during successful performance. However, due to the very limited sample size, the findings of this explorative study have to be interpreted cautiously.
\end{abstract}

Keywords: mental rotation; expertise in visual imagery; pen and paper vs. computer role-players; midline frontal theta band frequency activation; parietal alpha band frequency activation; gender influence; EEG

\section{Introduction}

Mental rotation is considered as a cognitive process that involves rotating matching mental images until being aligned to the match [1]. The mental rotation task (MRT) was classically introduced by Shepard and Metzler [2] and is considered to integrate both mental rotation and analytic strategies [1,3]. Analytic strategies that are seen to depend on working-memory-intensive visual comparison [1] contain identifying key stimuli features, registering their presence, absence, or change between figures [3]. Like for a physical rotation, the reaction time in mental rotation processes increases as the angular disparities become larger [1]. The analytical cognitive strategies used are dependent on visuospatial representation and visual working memory [1,3]. Depending on expertise and gender, individual differences in the performance have been found, as well as the electrocortical correlates of the mental rotation processes. In meta-analyses by Linn and Petersen [4], strong gender differences were observed in this special ability domain favoring men. Better and/or faster performances were often reported for men compared to women $[3,5]$; however, women were using more analytic and therefore different strategies than men [6-8]. Roberts and Bell [9] further examined gender differences in two- and three-dimensional 
MRT on paper and revealed that men's performance was better than women's, yet only in 3D tasks. However, the male advantage disappeared in true three-dimensional models of mental rotation compared to $2 \mathrm{D}$ prints of $3 \mathrm{D}$ objects $[10,11]$.

Gender differences in mental rotation performance can be diminished via training [11,12], although there might still be differences in reaction time [11]. Nevertheless, the positive impact of training was noted on performance and neural efficiency (decreased in cortical activation) in anteriofrontal and frontocentral areas [11]. However, it remains an open question as to whether persons who are highly trained in other sections of visual imagery would also benefit from training in very difficult mental rotation tasks, such as the redrawn Vandenberg and Kuse mental rotation test [13]. In particular, effects of intensive training remain largely unknown concerning performance as well as neural efficiency and the use of specific strategies.

\subsection{Visual Imagery and Pen and Paper Role-Playing}

Role-playing in general refers to taking on and playing fictional character roles in imaginary worlds or environments that are based on a real world. The main aim is to achieve identification with the fictional character or situation, which can be very instructive on the one hand but also very entertaining on the other. Role-playing can be divided into different categories, named mainly according to their exercise modality. Classically, a distinction is made between the "Pen and Paper Role-Playing Game" (P\&PRPG), the "Live-Action-Role-Playing Game" (LARP), the "Tabletop Role-Playing Game" and the "Computer Role-Playing Game", whereby the latter can be further differentiated into "Offline Computer Role-Playing Games" and "Massively Multi-Player Online Role-Playing Games", the so-called MMORPGs [14].

One role-playing game type that naturally needs a high skill in visual imagery is P\&PRPG. These games are characterized by the players acting in fictional stories with fictional characters, where the characters have certain basic characteristics, which have been noted down on the so-called character sheet and which define both the personality and certain achievements, skills and characteristics of the character [15]. In this type of role-playing game, the game master provides a story that is accessible to the players only verbally or with minor visual supports such as character portraits. Thus, in order to act in the story, the players must imagine the prevailing circumstances and experience the situations as well as the characters and their actions in mental imagination. Hence, in this scenario, visual imagery is a vital part of the gaming experience. In contrast, the newer computer-based role-playing games lack this kind of feature. In this type of game, the player is immersed into an often very complex audio-visual world with a usually complex plot. The gamer takes on the role of a fictional character who can act in a specific world. The computer generates a visual representation of the game world and the characters, so that the player only has to mentally imagine parts of the plot (cf. Hemminger, 2009) but not the visuospatial environment itself. In modern computer role-playing games, the graphic implementation of the game world, of the acting characters, and of the performed actions is very detailed. Thus, imagination becomes almost completely unnecessary for the development of a plot or a plot line. Although both types of role-players have similar contexts in their games, the specific demands concerning visual imagery are very different. Hence, these two groups were assessed in this study, with the pen and paper role-playing group as an expert group for mental imagery and the computer role-players as a matching control group. As we expected the pen and paper role-players to be quite good in a mental rotation task, we decided to use a rather difficult mental rotation task, the redrawn Vandenberg and Kuse test [13]. This was done to investigate the impact of training on the behavioral performance as well as on the electrocortical correlates concerning strategies and efficiency. 


\subsection{Frontal Theta}

Frontal midline theta activation can be measured in medial frontal areas in EEG of normal subjects when performing a broad range of cognitive tasks requiring mental concentrationfor example, cognitive control and active working memory maintenance [16-19]. The frontal midline theta originates from the anterior cingulate cortex and the medial prefrontal cortex $[1,17]$. Previous research provided evidence for enhanced activity in frontal midline theta $(4-8 \mathrm{~Hz})$ for increases in working memory processes as well as visual working memory load, which seems also associated with analytic strategies during a task according to findings with MRT [1,20]. Accordingly, as task difficulty increases, midfrontal theta indicates increased requirements for working memory maintenance and manipulation [1,17-19].

Hence, we were interested in whether there would be differences in the midfrontal theta in our expert groups and concerning gender. However, no clear hypotheses could be derived here, as on the one hand we would expect higher frontal midline theta for more difficult tasks $[1,20]$. Yet, experts in visual imagery may use different strategies than novices $[1,11]$, and neuronal efficiency may also influence the activity leading to lower activity in experts [11], who on the other hand may engage more in very difficult tasks where novices may already give up early. Thus, the findings concerning frequency measures, in general and midline frontal theta frequency band activation in particular, were more explorative than confirmatory. This is also true for other electrocortical correlates of strategy and performance.

\subsection{Parietal Alpha and Parietal Alpha Asymmetry}

As mental rotation also leads to a representation in visuospatial parietal areas, namely the superior parietal cortex [21], electrocortical signals at parietal sites are also relevant. The parietal activation plays a role in representing spatial maps, in action-oriented mental image construction and maintenance, as well as in updating spatial reference frames [21-23]. Since decreased activity in the alpha band is associated with increased functional activity in the underlying cortex, the alpha rhythm $(8-13 \mathrm{~Hz})$ has been used to indirectly measure the brain activation [24-27]. Hence, parietal alpha power was used to investigate the extent of the visuospatial representational demand of the mental rotation task $[1,9,11]$. A reduction in parietal alpha power is therefore associated with heightened use of visuospatial processing. Additionally, the right parietal cortex seems to be dominant in processing complex rotation tasks [9]. This effect has been found to be more pronounced for men than women. Yet, as these results were only attained with non-expert groups and in slightly different rotation tasks, our analyses were mostly exploratory.

Summing up our approach in the present study, we explored for the first time an expert group in mental imagery (pen and paper role-players: P\&PRPs) with a matched control group (computer role-players: CRPs) concerning their performance (correctness and speed) as well as their electrocortical correlates (midline frontal theta band activation, parietal alpha activation, and parietal alpha asymmetry) in a difficult mental rotation task. Additionally, we considered gender effects in our approach. Although being an exploratory study, we hypothesized firstly that males would perform faster and possibly more accurately, and secondly that mental imagery experts would perform better (faster and more accurately) than the control group. Concerning the electrocortical correlates, our study had a very exploratory perspective, as the influence of the task difficulty as well as the specific strategies of the participant groups were yet unpredictable. This is the first electrophysiological study measuring midline frontal theta activation and parietal alpha band activation using the very difficult Vandenberg and Kuse mental rotation task. Furthermore, this is also the first study combing the expert group of pen and paper role players with such a task design. 


\section{Materials and Methods}

\subsection{Ethical Statement}

The study was carried out in accordance with the recommendations of "Ethical guidelines, The Association of German Professional Psychologists" "Berufsethische Richtlinien, Berufsverband Deutscher Psychologinnen und Psychologen") with written informed consent from all subjects. All subjects gave written informed consent in accordance with the Declaration of Helsinki before they participated in the experiment. The protocol was not approved by any additional local ethics committee, for the used paradigm is common practice in psychological experiments. Furthermore, following \$7.3.2 of the "Ethical guidelines, The Association of German Professional Psychologists", the approval by an ethical committee is optional in Germany. As the local ethics committee is very busy, it does not deal with paradigms that are common practice and ethically uncritical. Additionally, the data collection was done in 2012, where a local ethics committee was not in place, and the local ethics committee does not support post hoc application.

\subsection{Participants}

Thirty right-handed participants (6 women and 24 men; 15 P\&PRPs and 15 CRPs) took part in the experiment. Each role-playing group contained an equal number of women and men. The recruiting of the participants was conducted according to the primary selection criterion, the role-playing type. After determining the P\&PRP group, a gender-matched CORP group was sampled. Due to the limitation concerning time and money of the recruitment, only 30 participants could be investigated, leading to this exploratory sample.

\subsection{Procedure}

Before the experiment, the participants filled in an online questionnaire using the generic HTML processor [28] for demographic data and questionnaires (see below). Then, the participants were invited into the lab based on their role-playing behavior. In the lab, the test subjects were informed about the experiment and an EEG was applied. Thereafter, an 8 min resting EEG was measured. Then, they were presented with three mental imagery scripts and tasks for spatial navigation during the first part of the experiment, which will not be addressed in this manuscript [29]. Subsequently, the participants experienced the mental rotation task. The test consisted of $2 \times 12$ items, with 4 min to complete the 12-item task. After the mental rotation task, several questionnaires were assessed (see trait questionnaires section below). Finally, the participants were compensated and farewelled.

\subsection{Paradigm}

The mental rotation task was an adaptation of the Vandenberg and Kuse rotation test in which the test subjects were asked to assess three-dimensional figures based on their correspondence with other figures [13]. The mental rotation test was taken from the test material by Peters and colleagues (1995) and brought into digital form to present it on the computer (see Figure 1).

The German version of the mental rotation test $C$ was used, in which the objects can be rotated around the $X$-axis as well as the $Y$-axis in space [13]. The test persons saw five different figures per test item: a target figure and four figures that were to be compared with the target figure. Two of the figures were a rotated form of the target figure, while two figures represented a rotated and mirrored form of the target figure. The participants needed to identify the two figures for each item that represented the rotated shape of the target figure. The test consisted of $2 \times 12$ items, with $4 \mathrm{~min}$ to complete the 12 -item task. Each item was presented individually on the monitor so that there were always five figures and a decision mask in which the test subjects could enter their answers by pressing a button. Answers were given using six different keys on the keyboard, each of which represented a combination of two of the four figures presented. Between the two blocks of mental rotation, there was a one-minute break. During the presentation of the rotation test, the EEG was recorded to measure alpha band and theta band activation. 
Look at the figure on the left:

Of the figures on the right, there are only

two identical figures to this figure.

Please select the identical figures

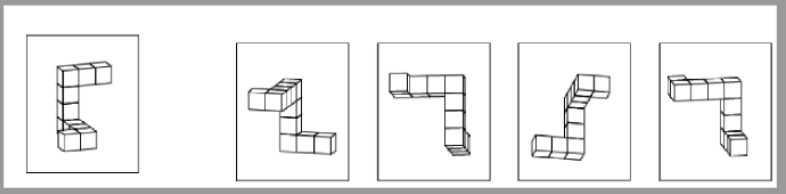

figures figures figures figures figures figures

\begin{tabular}{l|l|l|l|l|l}
$1+2$ & $1+3$ & $1+4$ & $2+3$ & $2+4$ & $3+4$
\end{tabular}

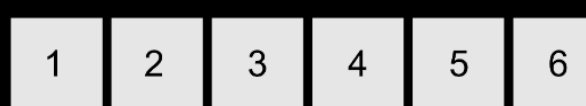

Figure 1. Schematic display of a trial of the mental rotation task.

The correctness of the answers and the speed of the answers to the mental rotation task were used as a measure of the spatial imagination performance. The activity of electrodes P4 and $\mathrm{P} 3$ in the alpha frequency band $(8-13 \mathrm{~Hz})$ during the rotation task and the midline theta (4-8 Hz) activation on the electrodes $\mathrm{Fz}$ and $\mathrm{Cz}$ were used as dependent variables $[9,11]$ as well as predictors for the behavioral performance (see also section below).

\subsection{Apparatus}

\subsubsection{EEG Recording and Pre-Processing}

The EEG was measured by $\mathrm{Ag} / \mathrm{AgCl}$-electrodes located in an electrode cap in the following 32 positions: Fp1, Fp2, F3, F4, F7, F8, F9, F10, Fz, FC1, FC2, FC5, FC6, C3, C4, T7, T6, CP1, CP, Pz, P3, P4, P7, P8, TP9, TP10, O1, O2, PO9, PO10, and Iz. (according to the international 10-10 system). Ground electrode was located on AFz position; the reference electrode was $\mathrm{Cz}$. An additional electrode to register eye movements and blinks was put below the left eye. Electrode impedances were kept below $5 \mathrm{kOhm}$ for the EEG. Data were recorded with a sampling rate of $250 \mathrm{~Hz}$ with BrainVision BrainAmp Standard (Brain Products GmbH, Gilching, Germany) and BrainVision Recorder 1.20 software (Brain Products $\mathrm{GmbH}$ ). For further computation, MATLAB and EEGLAB toolbox [30] and a variant of the EPOS pipeline was used [31]. Raw data were filtered with a $1 \mathrm{~Hz}$ Butterworth high-pass filter after statistical channel selection (z-value threshold 3.29) for frequency [1125 Hz], joint probability, and kurtosis. Deleted channels were spline extrapolated. The segmentation of the data was done from $-1 \mathrm{~s}$ before an event to $7 \mathrm{~s}$ after the start of each rotation task $-500 \mathrm{~ms}$ to the event onset. This time window was chosen because there were no reaction times below $7.7 \mathrm{~ms}$, leading to the same length of each segment and also possibly less motor-specific activation artifacts. Following the segmentation, a first ICA was performed, then artifact corrupted segments were detected and deleted statistically (z-value threshold 3.29), targeting all components for probability and kurtosis of the signal. Additional artifact correction for muscle activity and ocular correction was performed with a second ICA [32], removing all components associated with muscular activity or eye movement and blink activity by using the program SASICA [33] for selection with input from ADJUST [34] and MARA [35]. After that, CSD transformation was applied using a script provided by Cohen (2014). 
Theta frequency from $4-8 \mathrm{~Hz}$ was extracted using Morlet wavelets during the entire event period on the electrodes Fz and Cz. For midline theta, these two electrode theta activations were averaged. Parietal alpha $(8-13 \mathrm{~Hz})$ was extracted and averaged on electrodes P3 and P4 during the entire event period. For the extraction of the alpha-frequency as well as for the theta frequency, the scripts of the EPOS pipeline [31,36] were used, using Morlet wavelets with a cycle parameter of 3.5. The power output was absolute power and for further computation, the log of the absolute power was used.

\subsubsection{Trait Questionnaires and Demographical Data}

Demographical data (age, gender, role-playing behavior, computer-playing behavior, reading behavior, movie and television consumption) were recorded online before the experiment alongside the BIS-BAS scales [37] for behavioral activation and behavioral inhibition. After the experiment, a paper version of the NEO-FFI [38], a short verbal intelligence test [39], and the general depression scale [40] were assessed. The questionnaires were linked to the first part of the experimental task and were only assessed as control concepts for the groups in this case. Details on the differentiation of the role-playing group types can be seen in Table A1 in Appendix A.

\subsection{Statistical Analysis}

We predicted midline theta activation and parietal alpha activation using role-playing type (pen and paper/computer) and gender (man/woman) as predicting factors in two separate general linear models.

Concerning the resulting behavior, we analyzed the correct decision behavior with a general logistic model, using the role-playing type (pen and paper/computer) and gender (man/woman) as predicting factors, parietal alpha and midline theta as centered continuous predictors, and the correct decision as criterion.

Concerning the reaction time, we analyzed it using a general linear model with the role-playing type (pen and paper/computer) and gender (man/woman) as predicting factors, parietal alpha and midline theta as centered continuous predictors, and the reaction time as criterion.

For the post hoc analyses of higher interactions with continuous predictors, post hoc regressions were computed; for post hoc analyses of simple interactions, a simple Bonferroni-Holm corrected $t$-test was used. Due to the exploratory character of the study, no further corrections were used. The alpha level was $\alpha=0.05$. The software used for computation and illustration of the results was Jamovi [41].

\section{Results}

\subsection{Demographical Data}

Demographical data and the comparison between the groups can be seen in Table A1 in Appendix A section. The two groups were only significantly different firstly in age $(p=0.013)$, with P\&PRPs $(\mathrm{m}=26.867, \mathrm{SD}=4.307)$ being older than CORPs $(\mathrm{m}=23.2$, $\mathrm{SD}=3.212)$, and secondly in times per month role-playing $(p<0.001)$ with the P\&PRPs $(\mathrm{m}=3.3, \mathrm{SD}=1.953)$ playing less than CORPs $(\mathrm{m}=12.75, \mathrm{SD}=8.649)$. Marginal differences were found between the two groups in number of hours per month playing $(p=0.053)$ with the P\&PRPs $(\mathrm{m}=22, \mathrm{SD}=18.186)$ spending less hours playing than CORPs $(\mathrm{m}=50.5$, $\mathrm{SD}=51.463)$. Furthermore, the number of hours playing on the computer per month $(p=0.084)$ was also marginally different with P\&PRPs $(\mathrm{m}=26.3, \mathrm{SD}=37.113)$ spending less hours than CORPs $(\mathrm{m}=68.833, \mathrm{SD}=84.128)$. The number of hours spent playing Tetris and similar games per month $(p=0.093)$ was, however, marginally higher in P\&PRPs $(\mathrm{m}=2.367$, $\mathrm{SD}=4.592)$ than in the matched CORPs $(\mathrm{m}=0.284, \mathrm{SD}=0.7)$. Lastly, we observed a marginal difference in IQ score $(p=0.071)$ with P\&PRPs $(\mathrm{m}=117.733, \mathrm{SD}=12.736)$ scoring higher than CORPs $(\mathrm{m}=110.267, \mathrm{SD}=8.648)$. 


\subsection{Electrocortical Signal Prediction}

Midline theta was higher for women in general $\left(\mathrm{m}=12.042 \mu \mathrm{V}^{2} / \mathrm{m}^{2}, \mathrm{SE}=0.094 \mu \mathrm{V}^{2} / \mathrm{m}^{2}\right)$ compared to men $\left(\mathrm{m}=11.713 \mu \mathrm{V}^{2} / \mathrm{m}^{2}, \mathrm{SE}=0.042 \mu \mathrm{V}^{2} / \mathrm{m}^{2} ; \beta=0.366, t=3.202, p=0.001\right)$ and higher for P\&PRPs $\left(\mathrm{m}=12.062 \mu \mathrm{V}^{2} / \mathrm{m}^{2}, \mathrm{SE}=0.069 \mu \mathrm{V}^{2} / \mathrm{m}^{2}\right)$ vs. CORPs $\left(\mathrm{m}=11.693 \mu \mathrm{V}^{2} / \mathrm{m}^{2}\right.$, $\left.\mathrm{SE}=0.076 \mu \mathrm{V}^{2} / \mathrm{m}^{2} ; \beta=0.411, t=3.589, p<0.001\right)$. The interaction of role-playing type and gender was highly significant $(\beta=1.238, t=5.412, p<0.001)$, leading to no difference in midline theta for men $(p=0.165)$ and a higher theta activation for women with pen and paper role-playing experience compared to all others ( $p s<0.001$, see Figure 2). Topographical distribution during the entire time-period can be seen in Figure 3.
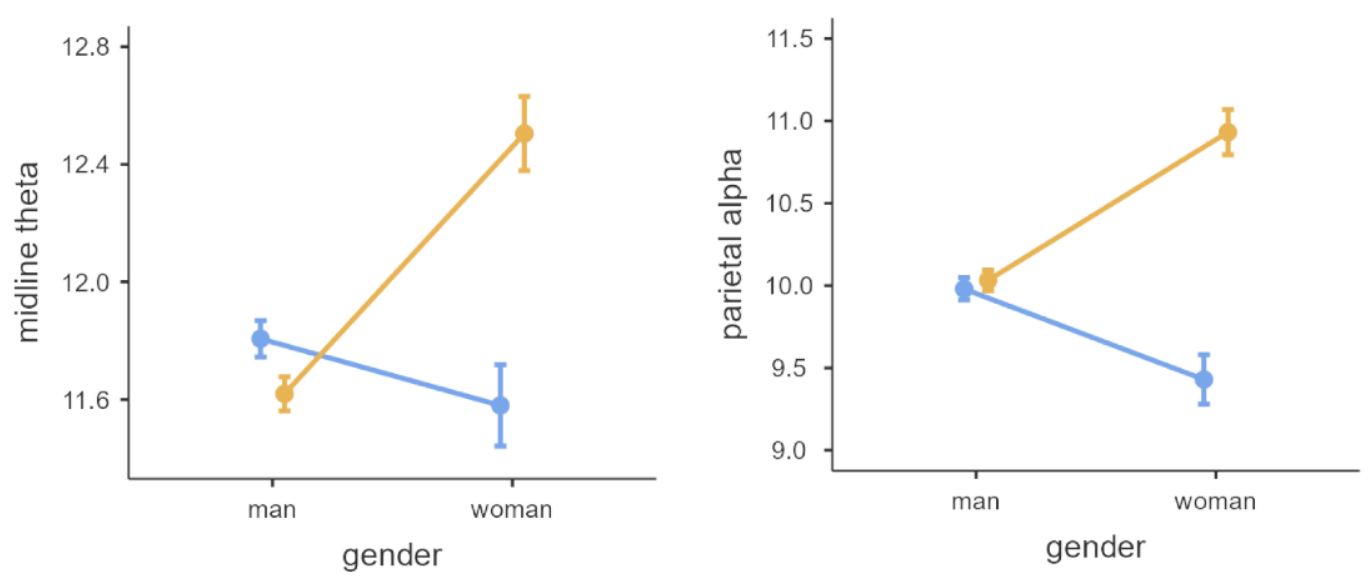

role-playing type (SE)

- computer

- pen \& paper

Figure 2. Midfrontal theta activation and parietal alpha activation: gender and role-playing type.
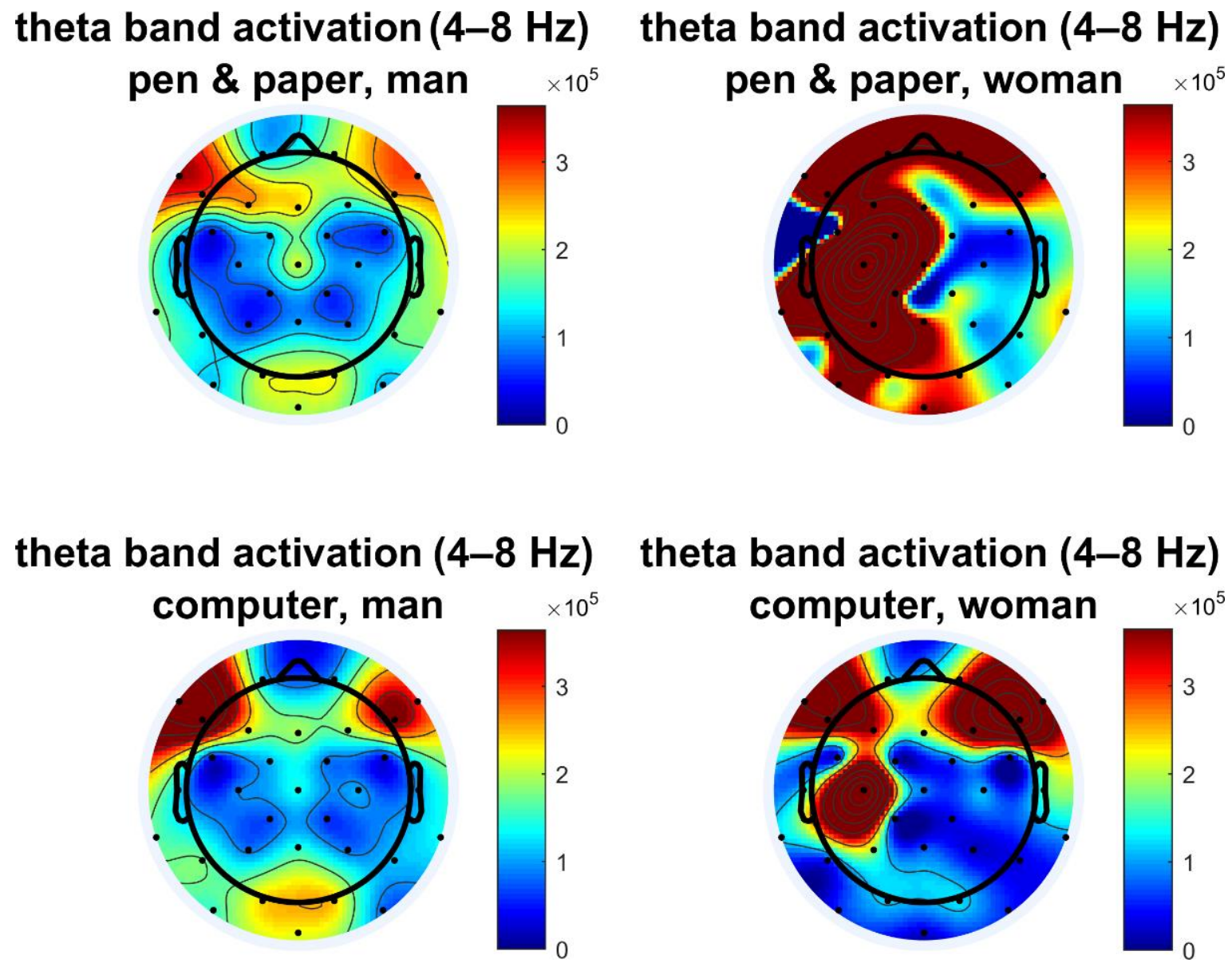

Figure 3. Topographical theta band activation during the entire timeframe from 1-7 s. 
For parietal alpha, identical effects were found for the role-playing type, with P\&PRPs having higher parietal alpha $\left(\mathrm{m}=10.482 \mu \mathrm{V}^{2} / \mathrm{m}^{2}, \mathrm{SE}=0.076 \mu \mathrm{V}^{2} / \mathrm{m}^{2}\right)$ than CORPs $\left(\mathrm{m}=9.705 \mu \mathrm{V}^{2} / \mathrm{m}^{2}, \mathrm{SE}=0.082 \mu \mathrm{V}^{2} / \mathrm{m}^{2}, \beta=0.784, t=6.953, p<0.001\right)$. Moreover, the interaction of role-playing type and gender was highly significant $(\beta=1.461, t=6.479$, $p<0.001)$, in this case leading again to no difference in parietal alpha for men $(p=1)$ but a higher alpha activation for women with pen and paper role-playing experience compared to all others ( $p s<0.001)$ and a lower alpha activation of women with computer role-playing experience ( $p s<0.006$, see Figure 2).

The parietal asymmetry depicted general right parietal activation, but less so for P\&PRPs $(\mathrm{m}=-0.284, \mathrm{SE}=0.075)$ vs. CORPs $(\mathrm{m}=-0.567, \mathrm{SE}=0.082, \beta=0.269, t=2.529$, $p=0.012)$. Interestingly, men in general had no clear lateral distribution concerning the parietal activation $(\mathrm{m}=0.083, \mathrm{SE}=0.046)$, while women showed the expected right parietal cortical activation $(\mathrm{m}=-0.934, \mathrm{SE}=0.102, \beta=-0.969, t=-9.106, p<0.001)$. This effect concerning men was further qualified by the role-playing group $(\beta=-0.587, t=-2.761$, $p=0.006$ ). Follow-up tests revealed that men had a weak relative right parietal cortical activation if playing computer role-playing games $(\mathrm{m}=-0.212, \mathrm{SE}=0.067)$, yet they had a significant relative left parietal cortical activation if they were P\&PRPs $(\mathrm{m}=0.379$, $\mathrm{SE}=0.063$, ps $<0.001$, see Figure 4 ).

Topographical distribution during the entire time-period can be seen in Figure 5.

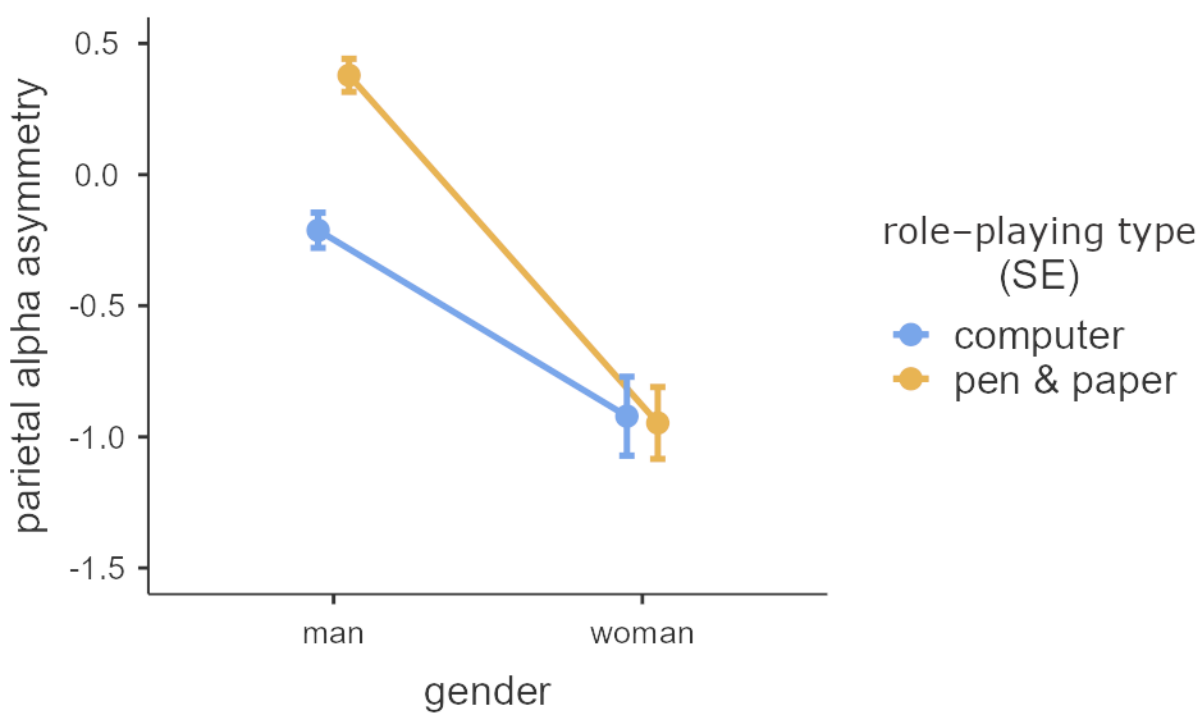

Figure 4. Parietal alpha asymmetry during rotation task: gender and role-playing type.

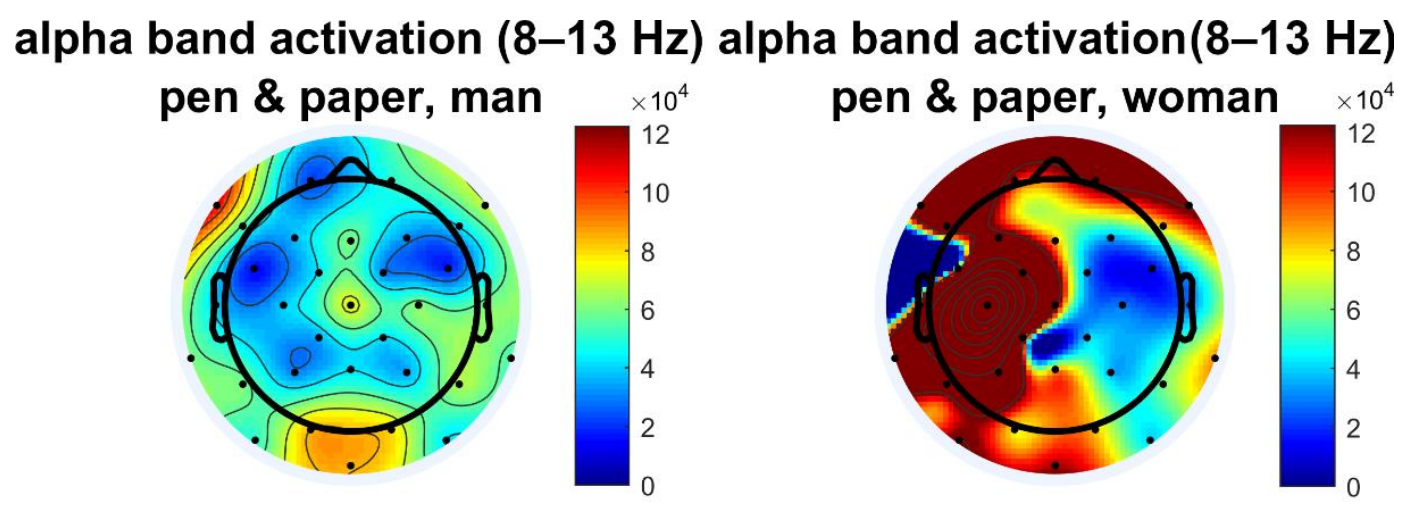

Figure 5. Cont. 


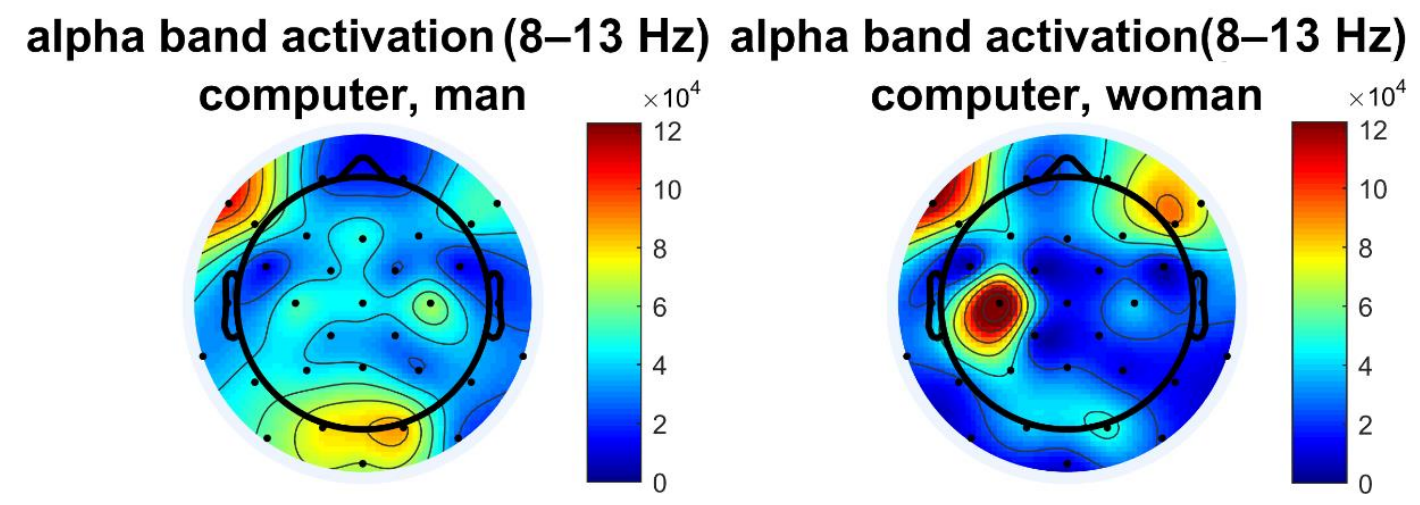

Figure 5. Topographical distribution of alpha activation during the entire time period from 1-7 s.

\subsection{Behavioral Prediction}

The correct response was predicted significantly by the interaction between roleplaying type and gender $(\exp (B)=10.018, z=3.166, p=0.002)$, with women who were CORPs performing worse than pen and paper role-playing women $(p=0.043)$, computer role-playing men $(p=0.003)$, and also marginally worse than men playing pen and paper $(p=0.056)$. For an illustration of the effect, see Figure 6.

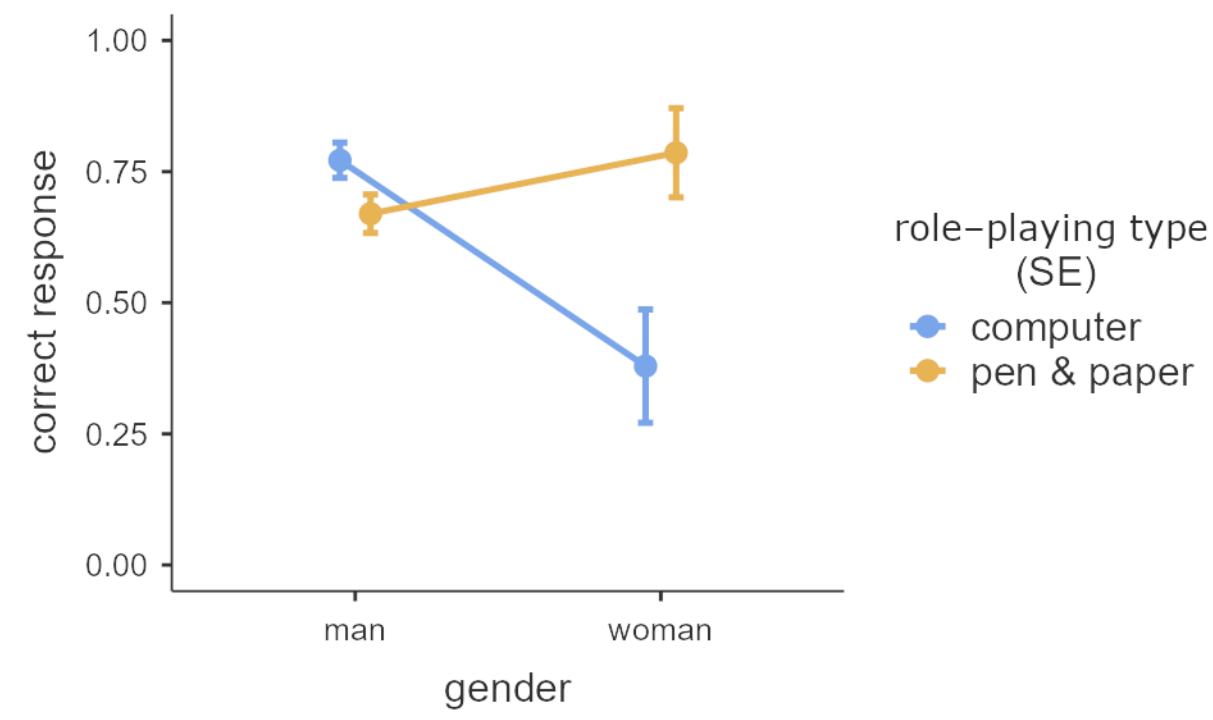

Figure 6. Correctness of the response in the mental rotation: gender and role-playing type.

Additionally, the interaction between role-playing type, gender, and parietal alpha $(\exp (B)=56.513, z=3.513, p=0.001)$ significantly predicted the correct response (see Figure 7 panel A). A higher parietal alpha led to more correct responses for P\&PRPs in men but less correct responses in male computer players $(\exp (B)=0.398, z=3.815, p<0.001)$. For women, this effect was reversed, yet due to statistical power, it was not significant $(\exp (B)=2.172, z=1.627, p=0.104)$ in the post hoc comparison.

Additionally, a marginal effect for the role-playing type was found with role-players performing marginally better $(\exp (B)=1.899, z=1.763, p=0.078)$. 

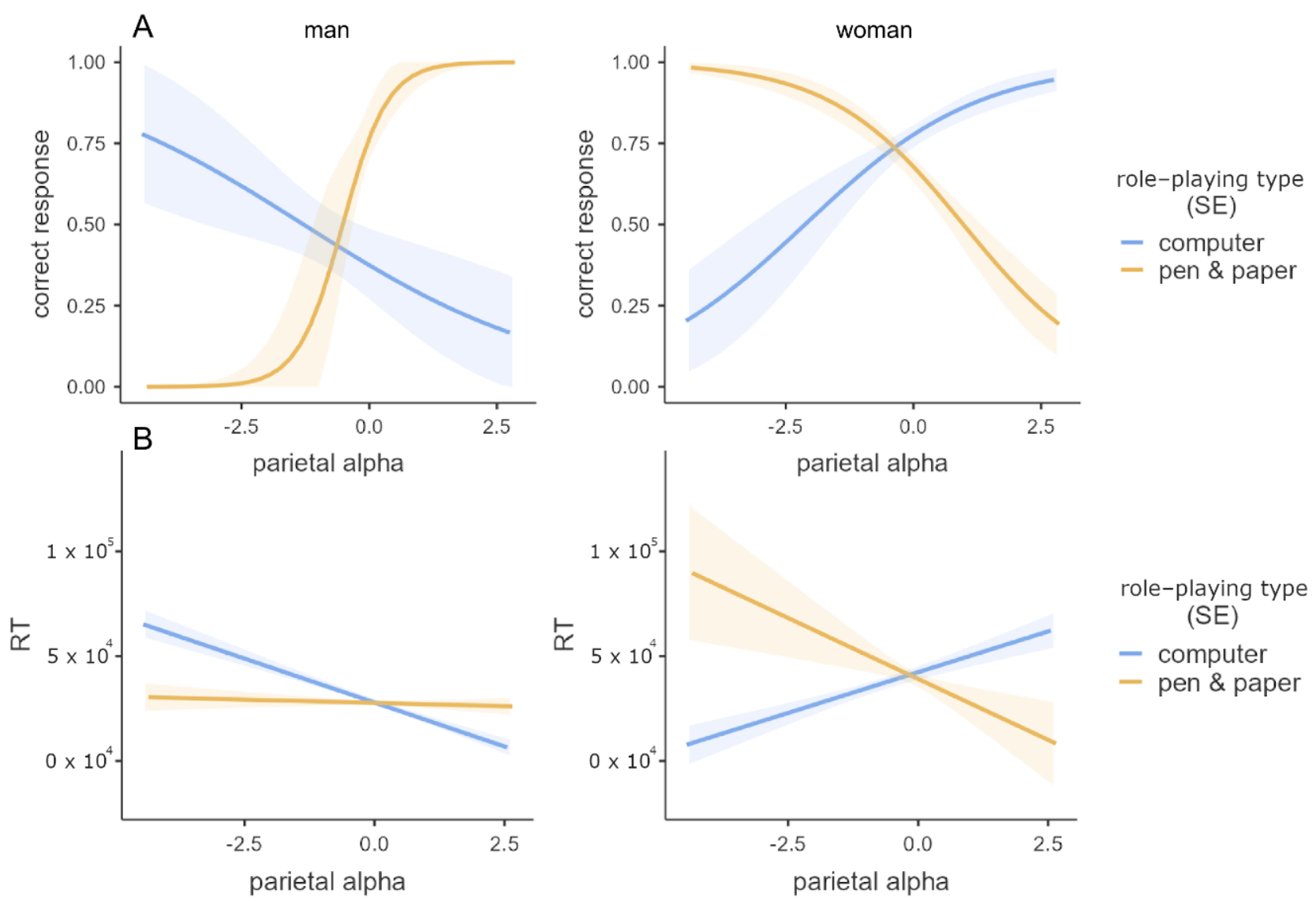

Figure 7. Correctness of the response and reaction time in $\mathrm{ms}$ in the mental rotation task: gender, role-playing type, and parietal alpha. (A) Correctness of the response and (B) reaction time.

The reaction time of the mental rotation task was predicted by gender $(\beta=0.671$, $t=5.112, p<0.001)$, with men $(\mathrm{m}=27,961 \mathrm{~ms}, \mathrm{SE}=855 \mathrm{~ms})$ being generally faster than women $(\mathrm{m}=\mathrm{ms}, \mathrm{SE}=2245 \mathrm{~ms})$. This effect interacted with midfrontal theta marginally ( $\beta=-0.335, t=-1.833, p=0.067)$, with higher midfrontal theta leading to faster performance in women $(\beta=-0.412, t=-4.150, p<0.001)$, while this effect was less pronounced for men $(\beta=-0.109, t=-2.229, p=0.026)$. The interaction of midline theta and parietal alpha significantly predicted the reaction time $(\beta=0.199, t=2.494, p=0.013)$. Post hoc regression analyses revealed that if midfrontal theta was high $(>1 \mathrm{SD})$, no predictive value was given for parietal alpha $(\beta=-0.063, t=-0.568, p=0.572)$, while if midfrontal theta was mediate $(<1 \mathrm{SD}$ and $>-1 \mathrm{SD} ; \beta=-0.161, t=-2.874, p=0.004)$ or low $(<-1 \mathrm{SD}$; $\beta=-0.553, t=-6.874, p<0.001)$, there were significant negative relations between the parietal alpha and reaction time (see Figure 8).

Like the correctness of the response, also the reaction time was influenced by the interaction of role-playing type, gender, and parietal alpha ( $\beta=-1.473, t=-3.419, p<0.001$, see Figure $7 \mathrm{~B})$. A higher parietal alpha led to no change in reaction time for P\&PRPs in men $(\beta=-0.074, t=-1.096, p=0.274)$ and to lower reaction time in men without this role-playing type $(\beta=-0.508, t=-8.216, p<0.001)$. For women, this effect was reversed, with parietal alpha being higher for lower reaction times in women with P\&PRP experience ( $\beta=-0.431, t=-3.202, p=0.003)$, while parietal alpha led to higher reaction times in women without P\&PRP experience ( $\beta=0.403, t=3.354, p=0.002)$. This three-fold interaction was moderated by the previous two-fold interaction of midline theta with parietal alpha, as it was less pronounced when midfrontal theta was high $(\beta=0.669, t=2.092$, $p=0.037)$. 


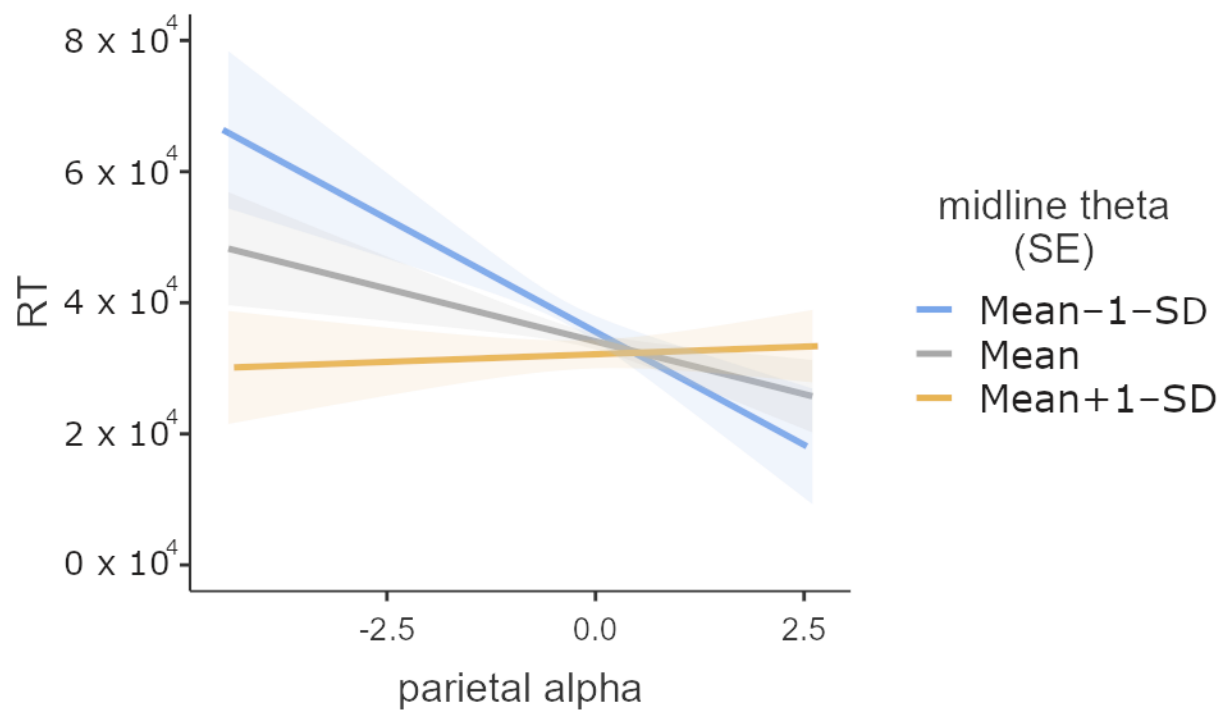

Figure 8. Reaction time in ms for mental rotation task: parietal alpha and midline frontal theta activation.

\section{Discussion}

In the present study, we investigated the behavioral performance (reaction time and correctness) as well as the electrocortical correlates of an expert group of mental imagery with a matched control group in a difficult mental rotation task. Additionally, we examined gender differences in our approach. As electrocortical correlates, we used midline frontal theta band activation, parietal alpha activation, and parietal alpha asymmetry. Results suggested higher levels of midline theta activation for women and for an expert group in mental imagery (pen and paper role-play). The expert group showed better performance in the task, although this effect was only marginally significant. In addition, higher theta activity was a correlate of faster reactions in both men and women. Moreover, the significant interaction of role-playing type and gender in midfrontal theta activation indicated higher theta activation in expert women, whereas men showed insignificant differences in theta activation in both groups of participants.

Previous research showed that an increase in midfrontal theta is associated with an increase in working memory demands in general. In particular, working memory maintenance and manipulation as well as visual working memory load is increased for higher theta, which is associated with analytical problem-solving strategies [1,17-19]. Moreover, women were found to use more analytical strategies [6-8]. Thus, in line with previous findings, our results might indicate that women use more analytical strategies especially when being highly skilled in visual imagery and when confronted with difficult mental rotation tasks. Possible analytic strategies that involve reasoning rather than mental manipulation can be seen as comparing the location, orientation, and features of the given figures with the original one [1,3]. In this case, segments of the given figure are selected and maintained in working memory while inspecting the other figures. Moreover, individuals using analytic strategies may consider all possible ways of pairing figure segments, hence resulting in working memory manipulation [1].

Focusing on parietal alpha, we observed higher levels of alpha activation in the expert group compared to the non-expert group. Moreover, men showed no significant differences in alpha activation in different role-playing types, whereas women exhibited higher levels of alpha activation when experienced in pen and paper role-playing. Training in mental rotation task has been proven to positively impact performance and led to decreased activation in frontal and frontocentral areas [11]. Accordingly, our findings suggest that training in a section of visual imagery rather than the mental rotation does also alter the neural efficiency (decreases in cortical activation). Yet, it is unclear whether this effect was due to different strategies or to neuronal efficiency; moreover, it was only present for women. 
In examining parietal asymmetry, a mixed result was observed. Right parietal asymmetry was observed in women and in the control group as expected [9]. Pen and paper playing men, in contrast, showed left parietal cortical activation. This did not align with previous findings. However, the findings may occur because of the long timeframe of the task as well as the specific strategies that may be used by the pen and paper role-playing men. For example, it was found that vivid mental imagery leads to higher left parietal activation [42] in contrast to the expected right parietal activation for mental rotation [9]. Hence, the P\&PRP men may have used a strategy that involved vivid imagination of the object of some kind, leading to more relative left parietal activation. This stresses the complexity of an interpretation of the asymmetry without controlling for the strategy, which we did not measure directly in our study.

On a behavioral level, the significant interaction between role-player type and gender suggested that only in female computer role-players, performance was reduced concerning classification accuracy. This supports the evidence that training and the use of different strategies can diminish the sex difference in mental rotation task $[6,8,11,12]$. Concerning performance speed, the expected difference was found with men being faster than women in this $2 \mathrm{D}$ representation of a $3 \mathrm{D}$ task $[5,8,10-12,43]$. This difference may be due to the different strategies used $[6,8,11,12]$ that also find representation in the differential importance of parietal alpha in performance accuracy and speed in our data concerning gender and expertise. While parietal alpha tended to be beneficial in pen and paper role-playing men and detrimental in CORPs, this relation was inversed in women. The benefit of parietal alpha may have come from using primary sensory cortices instead of the heteromodal association cortices [8], which would propagate a more bottom-up triggered approach in men than in women (see also Figure 5). As this strategy is better performed or more often chosen by the experts in men, the parietal alpha could be an active inhibition process [44-46] to enable an attention shift to the sensory input. This would enable a fast bottom-up triggered mental rotation performance using only sensory input and primary associative cortices. In contrast, women tend to use the parietal areas more as they want to involve the association cortices to perform a top-down oriented strategy [8]. Hence, less parietal alpha, especially in experts using this strategy, aligns with better performance (Figure 7). In accordance with this top-down strategy, women also express more midline frontal theta band activation, and their performance benefits more from higher midline theta (see also Figures 2 and 3). Hence, the differences in strategy dependent on gender and expertise can partly be found in behavioral performance as well as in electro-cortical activation patterns.

\section{Limitations}

There are several limitations to this study: First, our sample is very small (only 30 participants) and the gender distribution is very unfortunate, leading to only three women per expert group. Accordingly, gender differences and in particular findings in women in our study must be treated with caution, and we have focused any interpretation and discussion mainly on aspects that replicate previous research. Our analyses illustrate the general problem of measuring individual differences, since electrophysiological measures for single participants or small groups are always affected to a larger degree by noise than an average for larger groups of participants (see Figures 3 and 5, right as compared to left panels). Additionally, a marginal difference in IQ scores might have affected the better response in P\&PRPs, as higher spatial intelligence is associated with the ability to flexibly and automatically choose between mental simulation and more analytical form of thinking [1,3]. Accordingly, the expertise in games like Tetris was also marginally higher in P\&PRPs. However, due to the small sample size, we refrained from correcting for these background differences. Although future studies should aim to achieve equal gender distributions, the specific experimental and control group approach with role-players in this study led partly to this gender distribution, since women are a minority in these groups. Nevertheless, there was a good matching of the control group with the expertise group as they were both role-players, yet not for all control constructs. For example, probably due to 
the rather long tradition in pen and paper role-playing games (USA: 1971: "Chainmail" [47], 1973: “D\&D" [47]; Germany: 1978/1981: "Magira" /"Midgard" [48], 1984: "Das Schwarze Auge" [48]) and due to the game modus, pen and paper players were older and had higher openness scores. Future studies should try to avoid these differences. Moreover, future studies might want to extend the framework of application of this mental rotation task to other interesting groups, such as children or adolescents with learning disabilities, in order to use this task as a diagnostic tool [49]. Interestingly, in these groups, the gender distribution is similar than in our study and therefore the findings may be of value to create hypotheses in this specific case.

Concerning our task, we had a rather difficult task that has not been investigated in the context of alpha and theta frequency band activation so far. This task difficulty led to long reaction times (all $>7.5 \mathrm{~s}$ ) that made the analysis of the frequency response in the same time window partly questionable, as different processes might be shown there. However, as also different strategies were likely to be chosen, differences in the frequency bands are informative nevertheless, although one cannot be certain whether differences arose from different strategies or differences in timing of the response. Yet, in order to avoid confounding differences, the time window was not extended beyond the fastest reaction.

A final limitation is the neglection of the individual alpha frequency [25,49] (IAF). The IAF and the peak alpha frequency (PAF) have been identified to play an important role in working memory processes that may be used to solve the mental rotation task, especially in the case of this difficult Vandernberg and Kuse variation. It has also been shown that the PAF is sensitive to gender effects [50] and age, and is a marker of cognitive performance [51]. Yet, despite being dependent on age, the relation of PAF and cognitive performance stays the same over different age groups [51]. Hence, future studies with more participants could also investigate IAF and PAF, but due to our limited sample size and the very exploratory design in our study, we refrained from computing these measurements that are still connected to differential variables such as cognitive performance and age, in which we lack variance.

\section{Conclusions}

In the present explorative study, we showed that expertise in mental imagery due to pen and paper role-playing experience compared to computer gaming experience led to better performance as well as a more efficient strategy used in a difficult mental rotation task. Additionally, there was electro-cortical evidence for men using preferably bottom-up rotation strategies compared to women using top-down oriented strategies. Additionally, it could be shown that expertise in women can negate gender differences in performance accuracy, although gender-dependent performance speed differences were preserved due to the strategies used.

Author Contributions: Conceptualization, J.R.; methodology, J.R.; software, J.R.; validation, J.R., D.M., and J.H.; formal analysis, J.R.; investigation, J.R.; resources, J.H.; data curation, J.R.; writingoriginal draft preparation, J.R. and D.M.; writing — review and editing, J.R., D.M., and J.H.; visualization, J.R.; supervision, J.H.; project administration, J.R. All authors have read and agreed to the published version of the manuscript.

Funding: This research received no external funding.

Institutional Review Board Statement: Ethical review and approval were waived for this study, for the used paradigm is common practice in psychological experiments. Furthermore, following \$7.3.2 of the "Ethical guidelines, The Association of German Professional Psychologists", the approval by an ethical committee is optional in Germany. As the local ethics committee is very busy, it does not deal with paradigms that are common practice and ethically uncritical. Additionally, the data collection was done in 2012, where a local ethics committee was not in place, and the local ethics committee does not support post hoc application. Nevertheless, the study was carried out in accordance with the recommendations of "Ethical guidelines, The Association of German Professional Psychologists" ("Berufsethische Richtlinien, Berufsverband Deutscher Psychologinnen und Psychologen") with written informed consent from all subjects. 
Informed Consent Statement: All subjects gave written informed consent in accordance with the Declaration of Helsinki before they participated in the experiment.

Data Availability Statement: The data are available on request from the first author.

Acknowledgments: Thanks to Natalie Nagowski for part of the data collection and the participants for participating.

Conflicts of Interest: The authors declare no conflict of interest.

\section{Appendix A. Demographical Data}

Table A1. Demographical data of the two subject groups.

\begin{tabular}{|c|c|c|c|c|c|c|c|c|c|}
\hline Variable & Role-Playing Type & $\mathbf{N}$ & Mean & Median & SD & Minimum & Maximum & $t$ & $p$ \\
\hline \multirow[t]{2}{*}{ age } & computer & 15 & 23.2 & 22 & 3.212 & 19 & 30 & & \\
\hline & pen and paper & 15 & 26.867 & 26 & 4.307 & 22 & 39 & -2.643 & 0.013 \\
\hline \multirow{2}{*}{$\begin{array}{c}\text { years } \\
\text { role-playing }\end{array}$} & computer & 15 & 10 & 10 & 3.485 & 5 & 18 & & \\
\hline & pen and paper & 15 & 9.867 & 9 & 5.423 & 2 & 21 & 0.08 & 0.937 \\
\hline \multirow{2}{*}{$\begin{array}{l}\text { hours per month } \\
\text { role-playing }\end{array}$} & computer & 15 & 50.5 & 35 & 51.463 & 5 & 200 & & \\
\hline & pen and paper & 15 & 22 & 20 & 18.186 & 5 & 80 & 2.022 & 0.053 \\
\hline \multirow{2}{*}{$\begin{array}{l}\text { times per month } \\
\text { role-playing }\end{array}$} & computer & 15 & 12.75 & 12 & 8.649 & 3 & 30 & & \\
\hline & pen and paper & 15 & 3.3 & 3 & 1.953 & 1 & 8 & 4.128 & $<0.001$ \\
\hline \multirow{2}{*}{$\begin{array}{l}\text { reading time per } \\
\text { month in hours }\end{array}$} & computer & 15 & 17.967 & 10 & 17.919 & 0 & 60 & & \\
\hline & pen and paper & 15 & 23.933 & 15 & 22.795 & 1 & 80 & -0.797 & 0.432 \\
\hline \multirow[t]{2}{*}{$\begin{array}{l}\text { movie and TV } \\
\text { time per month } \\
\text { in hours }\end{array}$} & computer & 15 & 35.833 & 30 & 27.424 & 0 & 90 & & \\
\hline & pen and paper & 15 & 26.333 & 20 & 22.35 & 5 & 90 & 1.04 & 0.307 \\
\hline \multirow[t]{2}{*}{$\begin{array}{l}\text { computer } \\
\text { playing time per } \\
\text { month in hours }\end{array}$} & computer & 15 & 68.833 & 40 & 84.128 & 0 & 350 & & \\
\hline & pen and paper & 15 & 26.3 & 15 & 37.113 & 0 & 120 & 1.792 & 0.084 \\
\hline \multirow[t]{2}{*}{$\begin{array}{l}\text { Tetris and similar } \\
\text { games time per } \\
\text { month in hours }\end{array}$} & computer & 15 & 0.284 & 0 & 0.7 & 0 & 2 & & \\
\hline & pen and paper & 15 & 2.367 & 0 & 4.592 & 0 & 15 & -1.737 & 0.093 \\
\hline \multirow{2}{*}{$\begin{array}{l}\text { behavioral } \\
\text { inhibition }\end{array}$} & computer & 15 & 2.267 & 2.143 & 0.503 & 1.571 & 3.143 & & \\
\hline & pen and paper & 15 & 2.19 & 2 & 0.528 & 1.429 & 3.429 & 0.405 & 0.689 \\
\hline \multirow[t]{2}{*}{$\begin{array}{l}\text { behavioral } \\
\text { activation }\end{array}$} & computer & 15 & 1.954 & 1.923 & 0.341 & 1.462 & 2.769 & & \\
\hline & pen and paper & 15 & 2.082 & 2.154 & 0.27 & 1.538 & 2.385 & -1.14 & 0.264 \\
\hline \multirow[t]{2}{*}{ neuroticism } & computer & 15 & 1.711 & 1.5 & 0.813 & 0.333 & 3.25 & & \\
\hline & pen and paper & 15 & 1.817 & 1.917 & 0.622 & 0.667 & 3.083 & -0.399 & 0.693 \\
\hline \multirow[t]{2}{*}{ extraversion } & computer & 15 & 2.148 & 2.25 & 0.66 & 0.417 & 3.167 & & \\
\hline & pen and paper & 15 & 2.276 & 2.167 & 0.748 & 1.083 & 3.333 & -0.498 & 0.622 \\
\hline \multirow[t]{2}{*}{ openness } & computer & 15 & 2.694 & 3 & 0.563 & 1.75 & 3.5 & & \\
\hline & pen and paper & 15 & 3.106 & 3.167 & 0.343 & 2.25 & 3.5 & -2.415 & 0.023 \\
\hline \multirow[t]{2}{*}{ agreeableness } & computer & 15 & 2.606 & 2.5 & 0.5 & 1.833 & 3.583 & & \\
\hline & pen and paper & 15 & 2.611 & 2.667 & 0.511 & 1.667 & 3.333 & -0.03 & 0.976 \\
\hline \multirow[t]{2}{*}{ conscientiousness } & computer & 15 & 2.417 & 2.5 & 0.684 & 1.333 & 3.25 & & \\
\hline & pen and paper & 15 & 2.433 & 2.417 & 0.547 & 1.583 & 3.583 & -0.074 & 0.942 \\
\hline \multirow[t]{2}{*}{ IQ } & computer & 15 & 110.267 & 110 & 8.648 & 98 & 124 & & \\
\hline & pen and paper & 15 & 117.733 & 118 & 12.736 & 96 & 137 & -1.878 & 0.071 \\
\hline \multirow[t]{2}{*}{ depression } & computer & 15 & 17.733 & 14 & 11.448 & 3 & 34 & & \\
\hline & pen and paper & 15 & 12.067 & 9 & 9.483 & 3 & 42 & 1.476 & 0.151 \\
\hline
\end{tabular}




\section{References}

1. Gardony, A.L.; Eddy, M.D.; Brunyé, T.T.; Taylor, H.A. Cognitive strategies in the mental rotation task revealed by EEG spectral power. Brain Cogn. 2017, 118, 1-18. [CrossRef]

2. Shepard, R.N.; Metzler, J. Mental Rotation of Three-Dimensional. Objects. Sci. 1971, 171, 701-703. [CrossRef]

3. Geiser, C.; Lehmann, W.; Eid, M. Separating "Rotators" from “Nonrotators" in the Mental Rotations Test: A Multigroup Latent Class Analysis. Multivar. Behav. Res. 2006, 41, 261-293. [CrossRef]

4. Linn, M.C.; Petersen, A.C. Emergence and Characterization of Sex Differences in Spatial Ability: A Meta-Analysis. Child Dev. 1985, 56, 1479. [CrossRef]

5. Gootjes, L.; Bruggeling, E.C.; Magnée, T.; Van Strien, J.W. Sex differences in the latency of the late event-related potential mental rotation effect. NeuroReport 2008, 19, 349-353. [CrossRef]

6. Jordan, K. Women and men exhibit different cortical activation patterns during mental rotation tasks. Neuropsychologia 2002, 40, 2397-2408. [CrossRef]

7. Hugdahl, K.; Thomsen, T.; Ersland, L. Sex differences in visuo-spatial processing: An fMRI study of mental rotation. Neuropsychologia 2006, 44, 1575-1583. [CrossRef] [PubMed]

8. Butler, T.; Imperato-McGinley, J.; Pan, H.; Voyer, D.; Cordero, J.; Zhu, Y.-S.; Stern, E.; Silbersweig, D. Sex differences in mental rotation: Top-down versus bottom-up processing. NeuroImage 2006, 32, 445-456. [CrossRef]

9. Roberts, J.E.; Bell, M.A. Two- and three-dimensional mental rotation tasks lead to different parietal laterality for men and women. Int. J. Psychophysiol. 2003, 50, 235-246. [CrossRef]

10. McWilliams, W.; Hamilton, C.J.; Muncer, S.J. On Mental Rotation in Three Dimensions. Percept. Mot. Ski. 1997, 85, 297-298. [CrossRef] [PubMed]

11. Neubauer, A.C.; Bergner, S.; Schatz, M. Two- vs. Three-Dimensional Presentation of Mental Rotation Tasks: Sex Differences and Effects of Training on Performance and Brain Activation. Intelligence 2010, 38, 529-539. [CrossRef]

12. Kass, S.J.; Ahlers, R.H.; Dugger, M. Eliminating Gender Differences through Practice in an Applied Visual Spatial Task. Hum. Perform. 1998, 11, 337-349. [CrossRef]

13. Peters, M.; Laeng, B.; Latham, K.; Jackson, M.; Zaiyouna, R.; Richardson, C. A Redrawn Vandenberg and Kuse Mental Rotations Test-Different Versions and Factors That Affect Performance. Brain Cogn. 1995, 28, 39-58. [CrossRef] [PubMed]

14. Hemminger, E. The Mergence of Spaces: Experiences of Reality in Digital Role-Playing Games; Edition Sigma: Berlin, Germany, 2009.

15. Laws, R. Robin's Laws of Good Game Mastering; Steve Jackson Games: Austin, TX, USA, 2002.

16. Cavanagh, J.F.; Zambrano-Vazquez, L.; Allen, J.J.B. Theta lingua franca: A common mid-frontal substrate for action monitoring processes. Psychophysiology 2011, 49, 220-238. [CrossRef]

17. Cavanagh, J.F.; Frank, M.J. Frontal theta as a mechanism for cognitive control. Trends Cogn. Sci. 2014, 18, 414-421. [CrossRef] [PubMed]

18. Hsieh, L.-T.; Ranganath, C. Frontal midline theta oscillations during working memory maintenance and episodic encoding and retrieval. NeuroImage 2014, 85, 721-729. [CrossRef] [PubMed]

19. Maurer, U.; Brem, S.; Liechti, M.; Maurizio, S.; Michels, L.; Brandeis, D. Frontal Midline Theta Reflects Individual Task Performance in a Working Memory Task. Brain Topogr. 2015, 28, 127-134. [CrossRef] [PubMed]

20. Onton, J.; Delorme, A.; Makeig, S. Frontal midline EEG dynamics during working memory. NeuroImage 2005, 27, 341-356. [CrossRef]

21. Zacks, J.M. Neuroimaging Studies of Mental Rotation: A Meta-analysis and Review. J. Cogn. Neurosci. 2008, 20, 1-19. [CrossRef]

22. Sack, A.T.; Schuhmann, T. Hemispheric Differences within the Fronto-Parietal Network Dynamics Underlying Spatial Imagery. Front. Psychol. 2012, 3, 214. [CrossRef]

23. Sasaoka, T.; Mizuhara, H.; Inui, T. Dynamic Parieto-premotor Network for Mental Image Transformation Revealed by Simultaneous EEG and fMRI Measurement. J. Cogn. Neurosci. 2014, 26, 232-246. [CrossRef]

24. Stern, J.M. Simultaneous EEG and fMRI of the alpha rhythm. NeuroReport 2002, 13, 2487-2492. [CrossRef]

25. Klimesch, W. EEG alpha and theta oscillations reflect cognitive and memory performance: A review and analysis. Brain Res. Rev. 1999, 29, 169-195. [CrossRef]

26. Feige, B.; Scheffler, K.; Esposito, F.; Di Salle, F.; Hennig, J.; Seifritz, E. Cortical and Subcortical Correlates of Electroencephalographic Alpha Rhythm Modulation. J. Neurophysiol. 2005, 93, 2864-2872. [CrossRef]

27. Gonçalves, S.; de Munck, J.; Pouwels, P.; Schoonhoven, R.; Kuijer, J.; Maurits, N.; Hoogduin, J.; Van Someren, E.; Heethaar, R.; da Silva, F.L. Correlating the alpha rhythm to BOLD using simultaneous EEG/fMRI: Inter-subject variability. NeuroImage 2006, 30, 203-213. [CrossRef] [PubMed]

28. Göritz, A.S.; Birnbaum, M.H. Generic HTML Form Processor: A versatile PHP script to save Web-collected data into a MySQL database. Behav. Res. Methods 2005, 37, 703-710. [CrossRef] [PubMed]

29. Rodrigues, J. Helden Im Geiste: Visuelle Vorstellung Bei Pen E Paper-Rollenspielern_Eine EEG-Studie; Heroes in Mind: Visual Imagery in Pen \& Paper Role-Players -An EEG Study; Julius-Maximilians-Universität Würzburg: Würzburg, Germany, 2012.

30. Delorme, A.; Makeig, S. EEGLAB: An open source toolbox for analysis of single-trial EEG dynamics including independent component analysis. J. Neurosci. Methods 2004, 134, 9-21. [CrossRef]

31. Rodrigues, J.; Weiß, M.; Hewig, J.; Allen, J.J.B. EPOS: EEG Processing Open-Source Scripts. Front. Neurosci. 2021, 15, 663. [CrossRef]

32. Makeig, S.; Debener, S.; Onton, J.; Delorme, A. Mining Event-Related Brain Dynamics. Trends Cogn. Sci. 2004, 8, 204-210. [CrossRef] 
33. Chaumon, M.; Bishop, D.V.M.; Busch, N.A. A Practical Guide to the Selection of Independent Components of the Electroencephalogram for Artifact Correction. J. Neurosci. Methods 2015, 250, 47-63. [CrossRef]

34. Mognon, A.; Jovicich, J.; Bruzzone, L.; Buiatti, M. ADJUST: An Automatic EEG Artifact Detector Based on the Joint Use of Spatial and Temporal Features. Psychophysiology 2011, 48, 229-240. [CrossRef] [PubMed]

35. Winkler, I.; Haufe, S.; Tangermann, M. Automatic Classification of Artifactual ICA-Components for Artifact Removal in EEG Signals. Behav. Brain Funct. 2011, 7, 30. [CrossRef] [PubMed]

36. Cohen, M.X. Analyzing Neural Time Series Data Theory and Practice, 1st ed.; The MIT Press: Cambridge, MA, USA; London, UK, 2014

37. Carver, C.S.; White, T.L. Behavioral Inhibition, Behavioral Activation, and Affective Responses to Impending Reward and Punishment: The BIS/BAS Scales. J. Pers. Soc. Psychol. 1994, 67, 319-333. [CrossRef]

38. Costa, P.T.; McCrae, R.R. Revised NEO Personality Inventory (NEO-PI-R) and NEO Five-Factor Inventory (NEO-FFI); Psychological Assessment Resources: Odessa, FL, USA, 1992.

39. Lehrl, S. MWT-B-Mehrfachwahl-Wortschatz-Intelligenztest; Balingen Spitta-Verlag: Balingen, Germany, 2005.

40. Hautzinger, M.; Bailer, M. ADS-Allgemeine Depressionsskala; Hogrefe Verlag: Göttingen, Germany, 1993.

41. The Jamovi Project. Jamovi, Version 1.8. Computer Software. 2021. Available online: https://www.jamovi.org (accessed on 20 July 2021).

42. Marks, D.F.; Isaac, A.R. Topographical Distribution of EEG Activity Accompanying Visual and Motor Imagery in Vivid and Non-Vivid Imagers. Br. J. Psychol. 1995, 86, 271-282. [CrossRef]

43. Johnson, B.W.; McKenzie, K.J.; Hamm, J.P. Cerebral Asymmetry for Mental Rotation: Effects of Response Hand, Handedness and Gender. Neuroreport 2002, 13, 1929-1932. [CrossRef] [PubMed]

44. Foxe, J.J.; Snyder, A.C. The Role of Alpha-Band Brain Oscillations as a Sensory Suppression Mechanism during Selective Attention. Front. Psychol. 2011, 2, 154. [CrossRef]

45. Kelly, S.P.; Lalor, E.C.; Reilly, R.B.; Foxe, J.J. Increases in Alpha Oscillatory Power Reflect an Active Retinotopic Mechanism for Distracter Suppression during Sustained Visuospatial Attention. J. Neurophysiol. 2006, 95, 3844-3851. [CrossRef]

46. Klimesch, W.; Sauseng, P.; Hanslmayr, S. EEG Alpha Oscillations: The Inhibition-Timing Hypothesis. Brain Res. Rev. 2007, 53, 63-88. [CrossRef]

47. Fine, G.A. Shared Fantasy: Role Playing Games as Social Worlds; University of Chicago Press: Chicago, IL, USA, 2002.

48. Evers, M.; Finn, T. Magische Zeiten (Das Schwarze Auge); Erkrath Fantasy Productions: Erkrath, Germany, 2005.

49. Pérez-Elvira, R.; Oltra-Cucarella, J.; Carrobles, J.A.; Teodoru, M.; Bacila, C.; Neamtu, B. Individual Alpha Peak Frequency, an Important Biomarker for Live Z-Score Training Neurofeedback in Adolescents with Learning Disabilities. Brain Sci. 2021, 11, 167. [CrossRef]

50. Ghazi, T.R.; Blacker, K.J.; Hinault, T.T.; Courtney, S.M. Modulation of Peak Alpha Frequency Oscillations During Working Memory Is Greater in Females Than Males. Front. Hum. Neurosci. 2021, 15, 192. [CrossRef] [PubMed]

51. Clark, C.R.; Veltmeyer, M.D.; Hamilton, R.J.; Simms, E.; Paul, R.; Hermens, D.; Gordon, E. Spontaneous Alpha Peak Frequency Predicts Working Memory Performance across the Age Span. Int. J. Psychophysiol. 2004, 53, 1-9. [CrossRef] [PubMed] 